Kragujevac Journal of Mathematics

Volume 39(1) (2015), Pages 31-39.

\title{
ON NEIGHBOURLY IRREGULAR GRAPHS
}

\author{
H. B. WALIKAR ${ }^{1}$, S. B. HALKARNI ${ }^{2}$, H. S. RAMANE ${ }^{3}$, M. TAVAKOLI ${ }^{4}$, AND A. R. ASHRAFI ${ }^{5}$
}

\begin{abstract}
A connected graph $G$ is said to be neighbourly irregular graph if no two adjacent vertices of $G$ have same degree. In this paper we obtain neighbourly irregular subdivision graphs, line graphs and total graphs. The neighbourly irregularity of some graph products are also investigated.
\end{abstract}

\section{INTRODUCTION}

Throughout this paper we consider finite, simple, connected graphs. For graph theoretical terminology we follow the book [8]. Let $G$ be a graph with $n$ vertices and $m$ edges. The vertex set and edge set of $G$ are denoted by $V(G)$ and $E(G)$ respectively.

Let $\operatorname{deg}_{G}(v)$ denote the degree of a vertex $v$ in $G$. A graph $G$ is said to be regular if all its vertices have the same degree. A connected graph $G$ is said to be highly irregular if each neighbor of any vertex has different degree [1]. It is called $k$-neighbourhood regular if each vertex is adjacent to exactly $k$ vertices of the same degree [5]. The graph $G$ is said to be neighbourly irregular graph, abbreviated as NI graph, if no two adjacent vertices of $G$ have the same degree. This concept was introduced by Bhragsm and Ayyaswamy [6]. They constructed NI graphs of order $n$ for a given $n$ and a partition of $n$ with distinct parts and proved some properties of NI graphs related to graphoidal covering number, gracefulness, ply number, lace number, clique graph and minimal edge covering. The Figure 1 depicts an example of NI graph.

We now present some graph operations that will be used in this paper. Let $G$ and $H$ be two graphs. The join $G+H$ of graphs $G$ and $H$ with disjoint vertex sets $V_{1}$ and $V_{2}$ and edge sets $E_{1}$ and $E_{2}$ is the graph union $G \cup H$ together with all the edges joining $V_{1}$ and $V_{2}$. The Cartesian product of two graphs $G$ and $H$ is the graph $G \times H$

Key words and phrases. Neighbourly irregular graphs, subdivision graphs, line graphs, total garphs, graph products.

2010 Mathematics Subject Classification. Primary: 05C07. Secondary: 05C75.

Received: May 27, 2014

Accepted: March 4, 2015. 
whose vertex set is $V(G \times H)=V_{1} \times V_{2}$ and two vertices $\left(u_{1}, u_{2}\right)$ and $\left(v_{1}, v_{2}\right)$ are adjacent in $G \times H$ whenever $u_{1}=v_{1}$ and $u_{2}$ is adjacent to $v_{2}$ in $H$ or $u_{2}=v_{2}$ and $u_{1}$ is adjacent to $v_{1}$ in $G$. The corona product $G \circ H$ is obtained by taking one copy of $G$ and $|V(G)|$ copies of $H$; and by joining each vertex of the $i$-th copy of $H$ to the $i$-th vertex of $G, i=1,2, \cdots,|V(G)|$. The lexicographic product $G[H]$ of graphs $G$ and $H$ is the graph with vertex set $V(G) \times V(H)$ and $u=\left(u_{1}, v_{1}\right)$ is adjacent with $v=\left(u_{2}, v_{2}\right)$ whenever $\left(u_{1}\right.$ is adjacent to $\left.u_{2}\right)$ or $\left(u_{1}=u_{2}\right.$ and $v_{1}$ is adjacent to $\left.v_{2}\right)$. The tensor product of the graphs $G$ and $H$ is the graph $G \otimes H$ whose vertex set is $V(G \otimes H)=V_{1} \times V_{2}$ and two vertices $\left(u_{1}, u_{2}\right)$ and $\left(v_{1}, v_{2}\right)$ are adjacent in $G \otimes H$ if and only if $u_{1}$ is adjacent to $v_{1}$ in $G$ and $u_{2}$ is adjacent to $v_{2}$ in $H$, see for details [7].

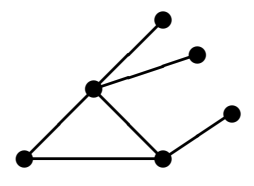

Figure 1: NI Graph.

Let $G$ and $H$ be graphs. The strong product $G \otimes H$ of graphs $G$ and $H$ is the graph with vertex set $V(G) \times V(H)$ and $u=\left(u_{1}, v_{1}\right)$ is adjacent with $v=\left(u_{2}, v_{2}\right)$ whenever $\left(v_{1}=v_{2}\right.$ and $u_{1}$ is adjacent with $\left.u_{2}\right)$ or $\left(u_{1}=u_{2}\right.$ and $v_{1}$ is adjacent with $\left.v_{2}\right)$ or $\left(u_{1}\right.$ is adjacent with $u_{2}$ and $v_{1}$ is adjacent with $v_{2}$ ), see [11] for details.

A graph $G$ with a specified vertex subset $U \subseteq V(G)$ is denoted by $G(U)$. Suppose $G$ and $H$ are graphs and $U \subseteq V(G)$. The generalized hierarchical product, denoted by $G(U) \sqcap H$, is the graph with vertex set $V(G) \times V(H)$ and two vertices $(g, h)$ and $\left(g^{\prime}, h^{\prime}\right)$ are adjacent if and only if $g=g^{\prime} \in U$ and $h h^{\prime} \in E(H)$ or, $g g^{\prime} \in E(G)$ and $h=h^{\prime}$. This graph operation introduced recently by Barriére et al. [3, 4] and found some applications in computer science. We encourage the reader to consult $[2,10]$ for mathematical properties and chemical applications of the hierarchical product of graphs.

In this paper we obtain neighbourly irregular subdivision graphs, line graphs and total graphs. The neighbourly irregular graphs obtained from some graph operations are also considered into account.

\section{Neighbourly Irregular Graphs}

The subdivision graph $S(G)$ of a graph $G$ is obtained from $G$ by inserting a new vertex onto every edge of $G[8]$.

Theorem 2.1. Let $G$ be a graph. The subdivision graph $S(G)$ is NI if and only if $G$ does not have any vertex of degree two.

Proof. Suppose $G$ does not have any vertex of degree two, i.e. for every vertex $u \in V(G), \operatorname{deg}_{G}(u) \neq 2$. If $u \in V(G)$ then $\operatorname{deg}_{G}(u)=\operatorname{deg}_{S(G)}(u)$. In $S(G)$ for every edge $e=u v$ in $G$, a new vertex $w$ is inserted and $\operatorname{deg}_{S(G)}(w)=2$. Therefore 
$\operatorname{deg}_{S(G)}(u) \neq \operatorname{deg}_{S(G)}(w)$ for every adjacent pair $(u, w)$ of the vertices of $S(G)$. Hence $S(G)$ is NI graph. Conversely, if $G$ is a graph with at least one vertex of degree two then $S(G)$ is not NI graph.

The line graph $L(G)$ of a graph $G$ is the graph whose vertices corresponds to the edges of $G$ and two vertices in $L(G)$ are adjacent if and only if the corresponding edges are adjacent in $G$ [8]. If $e=u v$ is an edge of $G$ then $\operatorname{deg}_{L(G)}(e)=\operatorname{deg}_{G}(u)+\operatorname{deg}_{G}(v)-2$. Let $N(u)$ denotes the set of vertices which are adjacent to $u$.

Theorem 2.2. For any graph $G$, its line graph $L(G)$ is $N I$ graph if and only if $N(u)$ contains all vertices of different degree for all $u \in V(G)$.

Proof. Let $L(G)$ be NI graph. To prove that $N(u)$ contains all vertices of different degree for all $u \in V(G)$, on the contrary, suppose $N(u)$ contains two vertices $v$ and $w$ of same degree, that is, $\operatorname{deg}_{G}(v)=\operatorname{deg}_{G}(w)$, where $v, w \in N(u)$. Therefore,

$$
\operatorname{deg}_{G}(u)+\operatorname{deg}_{G}(v)-2=\operatorname{deg}_{G}(u)+\operatorname{deg}_{G}(w)-2 .
$$

This implies that, $\operatorname{deg}_{L(G)}\left(e_{1}\right)=\operatorname{deg}_{L(G)}\left(e_{2}\right)$, where $e_{1}=u v$ and $e_{2}=u w$. Thus, $L(G)$ is not NI graph, a contradiction. Hence $N(u)$ contains all vertices of different degree.

Conversely, let $\operatorname{deg}_{G}(v) \neq \operatorname{deg}_{G}(w)$ for all $v, w \in N(u)$ and $u \in V(G)$. Therefore,

$$
\operatorname{deg}_{G}(u)+\operatorname{deg}_{G}(v)-2 \neq \operatorname{deg}_{G}(u)+\operatorname{deg}_{G}(w)-2 .
$$

That is, $\operatorname{deg}_{L(G)}\left(e_{1}\right) \neq \operatorname{deg}_{L(G)}\left(e_{2}\right)$, where $e_{1}=u v$ and $e_{2}=u w$. Hence $L(G)$ is NI graph.

Lemma 2.1. ([6]) If $u$ is a vertex of maximum degree in a NI graph then $N(u)$ contains at least two vertices of same degree.

Theorem 2.3. If $G$ is NI graph then $L(G)$ is not NI graph.

Proof. Let $u$ be the vertex of maximum degree in a NI graph $G$. Then by Lemma 2.1, $N(u)$ contains at least two vertices say $v$ and $w$ of same degree. The vertices $e_{1}=u v$ and $e_{2}=u w$ are adjacent in $L(G)$. But,

$$
\begin{aligned}
\operatorname{deg}_{L(G)}\left(e_{1}\right) & =\operatorname{deg}_{G}(u)+\operatorname{deg}_{G}(v)-2 \\
& =\operatorname{deg}_{G}(u)+\operatorname{deg}_{G}(w)-2 \\
& =\operatorname{deg}_{L(G)}\left(e_{2}\right) .
\end{aligned}
$$

Hence $L(G)$ is not NI graph.

Theorem 2.4. For each integer $k \geq 1$, there exists a graph $G$ with maximum degree $\Delta(G)=k$ such that $L(G)$ is NI graph.

Proof. Let $u$ and $v$ be two vertices of $G$ such that, $\operatorname{deg}_{G}(u)=\operatorname{deg}_{G}(v)=k$. Let the vertices $u_{1}, u_{2}, \ldots, u_{k-1}$ and $v$ be adjacent to $u$ and the vertices $v_{1}, v_{2}, \ldots, v_{k-1}$ and $u$ be adjacent to $v$, see Figure 2 . 


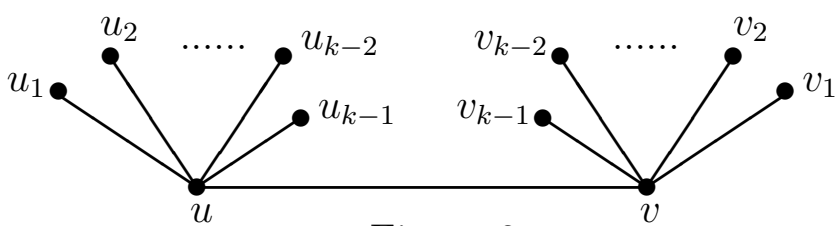

Figure 2

Join the vertices $u_{k-i}$ to the vertices $v_{i+1}, v_{i+2}, \ldots, v_{k-1}$ for $i=1,2, \ldots, k-2$. Thus the graph $G$ is obtained. It is not difficult to see that $\operatorname{deg}_{G}\left(u_{i}\right)=i$ for $i=1,2, \ldots, k-1$ and $\operatorname{deg}_{G}\left(v_{i}\right)=i$ for $i=1,2, \ldots, k-1$ and $\operatorname{deg}_{G}(u)=\operatorname{deg}_{G}(v)=k$.

Now $N\left(u_{i}\right)=\left\{u, v_{k-i+1}, v_{k-i+2}, \ldots, v_{k-1}\right\}$ and $\operatorname{deg}_{G}(u)=k$ and $\operatorname{deg}_{G}\left(v_{k-i+1}\right)=$ $k-i+1$ for $i=2,3, \ldots, k-1$. Hence $N\left(u_{i}\right)$ contains all vertices of different degrees, $i=1,2, \ldots, k-1$. Similarly we can show that $N\left(v_{i}\right)$ contains all vertices of different degrees for $i=1,2, \ldots, k-1$. Also $N(u)$ and $N(v)$ contains all vertices of different degrees. Hence by Theorem $2.2, L(G)$ is NI graph.

The total graph $T(G)$ of a graph $G$ is a graph whose vertex set is $V(G) \cup E(G)$ and two vertices in $T(G)$ are adjacent if and only if the corresponding elements are adjacent or incident in $G$ [8]. If $u$ is a vertex of $G$, then $\operatorname{deg}_{T(G)}(u)=2 \operatorname{deg}_{G}(u)$. If $e=u v$ is an edge of $G$ then $\operatorname{deg}_{T(G)}(e)=\operatorname{deg}_{G}(u)+\operatorname{deg}_{G}(v)$.

Theorem 2.5. For any graph $G$, the total graph $T(G)$ is $N I$ graph if and only if both $G$ and $L(G)$ are NI graphs.

Proof. Let the vertex set be $V(G)=\left\{v_{1}, v_{2}, \ldots, v_{n}\right\}$ and the edge set be $E(G)=$ $\left\{e_{1}, e_{2}, \ldots, e_{m}\right\}$. Suppose $G$ and $L(G)$ are NI graphs. In $T(G)$, let $e=x y$ be an edge then $x, y \in V(G)$ or $x, y \in E(G)$ or $x \in V(G)$ and $y \in E(G)$.

(a) $x, y \in V(G)$. Since $\operatorname{deg}_{G}(x) \neq \operatorname{deg}_{G}(y), \operatorname{deg}_{T(G)}(x)=2 \operatorname{deg}_{G}(x) \neq 2 \operatorname{deg}_{G}(y)=$ $\operatorname{deg}_{T(G)}(y)$.

(b) $x, y \in E(G)$. Let $x=v_{i} v_{j}$ and $y=v_{i} v_{k}$, so that $x$ and $y$ are adjacent in $T(G)$. Therefore $\operatorname{deg}_{T(G)}(x)=\operatorname{deg}_{G}\left(v_{i}\right)+\operatorname{deg}_{G}\left(v_{j}\right)$ and $\operatorname{deg}_{T(G)}(y)=\operatorname{deg}_{G}\left(v_{i}\right)+$ $\operatorname{deg}_{G}\left(v_{k}\right)$. But $\operatorname{deg}_{L(G)}(x) \neq \operatorname{deg}_{L(G)}(y)$ as $L(G)$ is NI graph. And $\operatorname{deg}_{L(G)}(x)=$ $\operatorname{deg}_{G}\left(v_{i}\right)+\operatorname{deg}_{G}\left(v_{j}\right)-2$ and $\operatorname{deg}_{L(G)}(y)=\operatorname{deg}_{G}\left(v_{i}\right)+\operatorname{deg}_{G}\left(v_{k}\right)-2$. Therefore $\operatorname{deg}_{T(G)}(x) \neq \operatorname{deg}_{T(G)}(y)$.

(c) $x \in V(G)$ and $y \in E(G)$. Let $e=x y=v_{i} e_{j}$ for some $v_{i} \in V(G)$ and $e_{j} \in E(G)$. Therefore $\operatorname{deg}_{T(G)}(x)=\operatorname{deg}_{T(G)}\left(v_{i}\right)=2 \operatorname{deg}_{G}\left(v_{i}\right)$ and

$$
\begin{aligned}
\operatorname{deg}_{T(G)}(y) & =\operatorname{deg}_{T(G)}\left(e_{j}\right)=\operatorname{deg}_{L(G)}\left(e_{j}\right)+2 \\
& =\operatorname{deg}_{G}\left(v_{i}\right)+\operatorname{deg}_{G}\left(v_{k}\right)-2+2, \text { where } e_{j}=v_{i} v_{k} \\
& =\operatorname{deg}_{G}\left(v_{i}\right)+\operatorname{deg}_{G}\left(v_{k}\right) \\
& \neq \operatorname{deg}_{G}\left(v_{i}\right)+\operatorname{deg}_{G}\left(v_{i}\right) \text { since } G \text { is NI graph, } \operatorname{deg}_{G}\left(v_{i}\right) \neq \operatorname{deg}_{G}\left(v_{k}\right) \\
& =2 \operatorname{deg}_{G}\left(v_{i}\right) \\
& =\operatorname{deg}_{T(G)}(x) .
\end{aligned}
$$


Thus in all cases $T(G)$ is NI graph.

Conversely, suppose $T(G)$ is NI graph. We have to prove that both $G$ and $L(G)$ are NI graphs. If $G$ is not NI graph, then there exists an edge $e_{k}=v_{i} v_{j}$ in $G$ such that $\operatorname{deg}_{G}\left(v_{i}\right)=\operatorname{deg}_{G}\left(v_{j}\right)$. So, $\operatorname{deg}_{T(G)}\left(v_{i}\right)=\operatorname{deg}_{T(G)}\left(v_{j}\right)$. A contradiction to $T(G)$ is NI graph.

Suppose $L(G)$ is not NI graph, then there exists two adjacent vertices $e_{i}=v_{r} v_{s}$ and $e_{j}=v_{r} v_{k}$ in $L(G)$ with $\operatorname{deg}_{L(G)}\left(e_{i}\right)=\operatorname{deg}_{L(G)}\left(e_{j}\right)$. Thus, $\operatorname{deg}_{G}\left(v_{r}\right)+\operatorname{deg}_{G}\left(v_{s}\right)-2=$ $\operatorname{deg}_{G}\left(v_{r}\right)+\operatorname{deg}_{G}\left(v_{k}\right)-2$. Hence $\operatorname{deg}_{G}\left(v_{r}\right)+\operatorname{deg}_{G}\left(v_{s}\right)=\operatorname{deg}_{G}\left(v_{r}\right)+\operatorname{deg}_{G}\left(v_{k}\right)$ and so $\operatorname{deg}_{T(G)}\left(e_{i}\right)=\operatorname{deg}_{T(G)}\left(e_{j}\right)$. Again a contradiction to $T(G)$ is NI graph.

From Theorems 2.3 and 2.5 we have following result:

Theorem 2.6. There is no nontrivial graph $G$ whose total graph $T(G)$ is NI graph.

\section{Neighbourly Irregular Graph Products}

Let $G_{1}$ be the graph with vertex set $V_{1}=V\left(G_{1}\right)$ and edge set $E_{1}=E\left(G_{1}\right)$. Let $G_{2}$ be the another graph with vertex set $V_{2}=V\left(G_{2}\right)$ and edge set $E_{2}=E\left(G_{2}\right)$. If $(u, v) \in V\left(G_{1} \times G_{2}\right)$ then $\operatorname{deg}_{G_{1} \times G_{2}}((u, v))=\operatorname{deg}_{G_{1}}(u)+\operatorname{deg}_{G_{2}}(v)$.

Theorem 3.1. For any two graphs $G$ and $H$, the Cartesian product $G \times H$ is $N I$ graph if and only if both $G$ and $H$ are NI graphs.

Proof. Let $G$ and $H$ be the NI graphs. Let $N(u)=\left\{u_{1}, u_{2}, \ldots, u_{k}\right\}$ and $N(v)=$ $\left\{v_{1}, v_{2}, \ldots, v_{l}\right\}$, where $u \in V(G)$ and $v \in V(H)$. Then by definition of NI graph $\operatorname{deg}_{G}(u) \neq \operatorname{deg}_{G}\left(u_{i}\right)$ for $i=1,2, \ldots, k$ and $\operatorname{deg}_{H}(v) \neq \operatorname{deg}_{H}\left(v_{j}\right)$ for $j=1,2, \ldots, l$. The vertex set of $G \times H$ is $V(G) \times V(H)$. Clearly,

$$
N((u, v))=\left\{\left(u_{i}, v\right),\left(u, v_{j}\right) \mid i=1,2, \ldots, k \text { and } j=1,2, \ldots, l\right\} .
$$

To prove that $G \times H$ is NI graph, on the contrary $G \times H$ is not NI graph. Then there exists at least one vertex in $N((u, v))$ with same degree as the degree of the vertex $(u, v)$ in $G \times H$. Hence $\operatorname{deg}_{G \times H}((u, v))=\operatorname{deg}_{G \times H}\left(\left(u_{i}, v\right)\right)$ and so $\operatorname{deg}_{G}(u)+\operatorname{deg}_{H}(v)=$ $\operatorname{deg}_{G}\left(u_{i}\right)+\operatorname{deg}_{H}(v)$. This implies that $\operatorname{deg}_{G}(u)=\operatorname{deg}_{G}\left(u_{i}\right)$. A contradiction to the fact that $G$ is NI graph. Similarly we can show that a contradiction to the fact that $H$ is NI graph. Hence $G \times H$ is NI graph.

Conversely, suppose $G \times H$ is NI graph. Let $N(u)=\left\{u_{1}, u_{2}, \ldots, u_{k}\right\}$ and $N(v)=$ $\left\{v_{1}, v_{2}, \ldots, v_{l}\right\}$, where $u \in V(G)$ and $v \in V(H)$. Therefore,

$$
\operatorname{deg}_{G \times H}((u, v)) \neq \operatorname{deg}_{G \times H}\left(\left(u_{i}, v\right)\right),
$$

where $\left(u_{i}, v\right) \in N((u, v))$. This shows that $\operatorname{deg}_{G}(u)+\operatorname{deg}_{H}(v) \neq \operatorname{deg}_{G}\left(u_{i}\right)+\operatorname{deg}_{H}(v)$ and so $\operatorname{deg}_{G}(u) \neq \operatorname{deg}_{G}\left(u_{i}\right)$. Hence $G$ is NI graph. Similarly we can show that $H$ is NI graph.

In the next theorem, the tensor product of graphs are considered. We notice that if $(u, v) \in V(G \otimes H)$ then $\operatorname{deg}_{G \otimes H}((u, v))=\operatorname{deg}_{G}(u) \operatorname{deg}_{H}(v)$. 
Theorem 3.2. For any NI graph $G$ and a regular graph $H$, the tensor product $G \otimes H$ is NI graph.

Proof. Let $G$ be the NI graph and $H$ be any regular graph of degree $r$. Let $N(u)=$ $\left\{u_{1}, u_{2}, \ldots, u_{k}\right\}$ where $u \in V(G)$ and $N(v)=\left\{v_{1}, v_{2}, \ldots, v_{r}\right\}$, where $v \in V(H)$. Since $G$ is NI graph, $\operatorname{deg}_{G}(u) \neq \operatorname{deg}_{G}\left(u_{i}\right), i=1,2, \ldots, k$.

On the contrary, suppose $G \otimes H$ is not NI graph, then there exists at least two adjacent vertices of same degree in $G \otimes H$. Without loss of generality, suppose $\operatorname{deg}_{G \otimes H}((u, v))=\operatorname{deg}_{G \otimes H}\left(\left(u_{i}, v_{j}\right)\right)$, where $i=1,2, \ldots, k$ and $j=1,2, \ldots, r$. Hence, $\operatorname{deg}_{G}(u) \operatorname{deg}_{H}(v)=\operatorname{deg}_{G}\left(u_{i}\right) \operatorname{deg}_{H}\left(v_{j}\right)$ and so $\operatorname{deg}_{G}(u) \operatorname{deg}_{H}(v)=\operatorname{deg}_{G}\left(u_{i}\right) \operatorname{deg}_{H}(v)$. Since $H$ is a regular graph, $\operatorname{deg}_{H}(v)=\operatorname{deg}_{H}\left(v_{j}\right)=r$ and so $\operatorname{deg}_{G}(u)=\operatorname{deg}_{G}\left(u_{i}\right)$, a contradiction to the fact that $G$ is NI graph. Hence $G \otimes H$ is NI graph.

Suppose $G$ is a graph. The set of all vertex degrees of $G$ is called the vertex degree set of $G$.

Theorem 3.3. Let $G$ and $H$ be graphs with vertex degree sets $S_{G}$ and $S_{H}$, respectively. Then $G+H$ is NI graph if and only if both $G$ and $H$ are NI graphs and, $(|V(G)|=$ $|V(H)|$ and $\left.S_{G} \cap S_{H}=\varnothing\right)$ or $\left(|V(G)|-|V(H)|=t>0\right.$ and $S_{G} \cap\left\{a_{i}+t \mid a_{i} \in\right.$ $\left.\left.S_{H}\right\}=\varnothing\right)$.

Proof. If both $G$ and $H$ are NI graphs and, $|V(G)|=|V(H)|$ and $S_{G} \cap S_{H}=\varnothing$, or, $|V(G)|-|V(H)|=t>0$ and $S_{G} \cap\left\{a_{i}+t \mid a_{i} \in S_{H}\right\}=\varnothing$, it is clear that $G+H$ is NI graph. So, it is enough to prove that if $G+H$ is NI graph, then both $G$ and $H$ are NI graphs and, $|V(G)|=|V(H)|$ and $S_{G} \cap S_{H}=\varnothing$, or, $|V(G)|-|V(H)|=t>0$ and $S_{G} \cap\left\{a_{i}+t \mid a_{i} \in S_{H}\right\}=\varnothing$. By definition of $G+H$, it is clear that if $G+H$ is NI graph, then both $G$ and $H$ are NI graphs. Now, there are two separate cases as follows:

(a) $|V(G)|=|V(H)|$. Let $u \in V(G)$. So, by definition of join of two graphs, $u$ is adjacent to each vertex in copy of $H$ in $G+H$ and since $G+H$ is NI graph, therefore, $\operatorname{deg}_{G+H}(u)-\operatorname{deg}_{G+H}(v)=\operatorname{deg}_{G}(u)-\operatorname{deg}_{H}(v) \neq 0$, for each $v$ in copy of $H$. This implies that $S_{G} \cap S_{H}=\varnothing$.

(b) $|V(G)|-|V(H)|=t>0$. Suppose $u \in V(G)$, so again by definition of join of two graphs, $u$ is adjacent to each vertex in the copy of $H$ in $G+H$ and since $G+H$ is NI graph, thus, $\operatorname{deg}_{G+H}(u)-\operatorname{deg}_{G+H}(v)=\operatorname{deg}_{G}(u)+|V(H)|-$ $\operatorname{deg}_{H}(v)-|V(G)|=\operatorname{deg}_{G}(u)-\operatorname{deg}_{H}(v)-t \neq 0$, for each $v$ in the copy of $H$. Therefore, $\operatorname{deg}_{G}(u) \neq \operatorname{deg}_{H}(v)+t$, for each $v$ in copy of $H$. This means that $S_{G} \cap\left\{a_{i}+t \mid a_{i} \in S_{H}\right\}=\varnothing$.

By Cases (a) and (b), the proof is completed.

To prove the next result, we have to present some notations. Let $G^{\prime}$ be a copy of $G$ and $H_{i}$ be the $i$-th copy of $H$ in $G \circ H, 1 \leq i \leq|V(G)|$. Then, $G \circ H$ is obtained by joining each vertex of the $i$-th copy of $H$ to the $i$-th vertex $\left(x_{i}\right)$ of $G$. A vertex of $G \circ H$ corresponding to the vertex $u$ in $H$ is denoted by $u^{\prime}$. Also, we denote a vertex of $G \circ H$ corresponding to the vertex $v$ in $G$ by $v^{\prime}$. 
Theorem 3.4. Let $G$ and $H$ be nontrivial graphs. Then $G \circ H$ is NI graph if and only if both $G$ and $H$ are NI graphs.

Proof. Let $G$ and $H$ be NI nontrivial graphs. Then it is clear that $G \circ H$ is NI graph. Conversely, let $G$ and $H$ be two nontrivial graphs and $G \circ H$ is NI graph. Suppose $u^{\prime} v^{\prime} \in E(G \circ H)$ such that $u^{\prime}, v^{\prime} \in V\left(H_{i}\right)$, then $\operatorname{deg}_{G \circ H}\left(u^{\prime}\right)-\operatorname{deg}_{G \circ H}\left(v^{\prime}\right)=$ $\operatorname{deg}_{H}(u)-\operatorname{deg}_{H}(v) \neq 0$ and so $H$ is NI graph. On the other hand, if $u^{\prime} v^{\prime} \in E(G \circ H)$ such that $u^{\prime}, v^{\prime} \in V\left(G^{\prime}\right)$, then $\operatorname{deg}_{G \circ H}\left(u^{\prime}\right)-\operatorname{deg}_{G \circ H}\left(v^{\prime}\right)=\operatorname{deg}_{G}(u)-\operatorname{deg}_{G}(v) \neq 0$. Therefore, $G$ is NI graph.

Theorem 3.5. Let $G$ and $H$ be nontrivial graphs. Then $G[H]$ is NI graph if and only if both $G$ and $H$ are NI graphs.

Proof. By definition of lexicographic product $G[H]$ we have that $\operatorname{deg}_{G[H]}((u, v))=$ $\operatorname{deg}_{G}(u)|V(H)|+\operatorname{deg}_{H}(v)$ for each $(u, v) \in V(G[H])$. Thus, if $G$ and $H$ are NI graphs, it is clear that $G[H]$ is NI graph. Conversely, let $G[H]$ be NI graph. So, for every $\left(u, v_{1}\right)\left(u, v_{2}\right) \in E(G[H])$ that $v_{1} v_{2} \in E(H)$ and $u \in V(G), \operatorname{deg}_{G[H]}\left(\left(u, v_{1}\right)\right)-$ $\operatorname{deg}_{G[H]}\left(\left(u, v_{2}\right)\right)=\operatorname{deg}_{H}\left(v_{1}\right)-\operatorname{deg}_{H}\left(v_{2}\right) \neq 0$, that is $\operatorname{deg}_{H}\left(v_{1}\right) \neq \operatorname{deg}_{H}\left(v_{2}\right)$ for every $v_{1} v_{2} \in E(H)$. Therefore, $H$ is NI graph. On the other hand, for every $\left(u_{1}, v\right)\left(u_{2}, v\right) \in$ $E(G[H])$ that $u_{1} u_{2} \in E(G)$ and $v \in V(H), \operatorname{deg}_{G[H]}\left(\left(u_{1}, v\right)\right)-\operatorname{deg}_{G[H]}\left(\left(u_{2}, v\right)\right)=$ $|V(H)|\left(\operatorname{deg}_{G}\left(u_{1}\right)-\operatorname{deg}_{G}\left(u_{2}\right)\right) \neq 0$. This means that $\operatorname{deg}_{G}\left(u_{1}\right) \neq \operatorname{deg}_{G}\left(u_{2}\right)$ for every $u_{1} u_{2} \in E(G)$. Therefore, $G$ is NI graph, which completes the proof.

Theorem 3.6. Let $G$ and $H$ be nontrivial graphs and let $U$ be a nonempty subset of $V(G)$. Then $G(U) \sqcap H$ is NI graph if and only if $H$ is NI graph and for each $g_{1} g_{2} \in E(G)$ and $v \in V(H)$,

$$
\operatorname{deg}_{G}\left(g_{2}\right)-\operatorname{deg}_{G}\left(g_{1}\right) \neq \begin{cases}0, & \text { if } g_{1}, g_{2} \in U \text { or } g_{1}, g_{2} \in V(G)-U, \\ \operatorname{deg}_{H}(v), & \text { if } g_{1} \in U \text { and } g_{2} \in V(G)-U .\end{cases}
$$

Proof. Let $G$ and $H$ be two nontrivial graphs and let $U$ be a nonempty subset of $V(G)$. If $g \in U$ and $h \in V(H)$, then by definition of generalized hierarchical product, $\operatorname{deg}_{G(U) \sqcap H}((g, h))=\operatorname{deg}_{G}(g)+\operatorname{deg}_{H}(h)$. Similarly, if $g \in V(G)-U$, then $\operatorname{deg}_{G(U) \sqcap H}((g, h))=\operatorname{deg}_{G}(g)$. Thus, if $H$ is NI graph and the inequality given in the statement of this theorem is satisfied, then clearly $G(U) \sqcap H$ is NI graph. Conversely, let $G(U) \sqcap H$ be NI graph. Suppose $\left(g_{1}, h_{1}\right)\left(g_{2}, h_{2}\right) \in E(G(U) \sqcap H)$. If $g_{1}=g_{2} \in U$ and $h_{1} h_{2} \in E(H)$, then $\operatorname{deg}_{G(U) \sqcap H}\left(\left(g_{1}, h_{1}\right)\right)-\operatorname{deg}_{G(U) \sqcap H}\left(\left(g_{1}, h_{2}\right)\right)=\operatorname{deg}_{H}\left(h_{1}\right)-\operatorname{deg}_{H}\left(h_{2}\right)$ and since $G(U) \sqcap H$ is NI graph, thus $\operatorname{deg}_{H}\left(h_{1}\right)-\operatorname{deg}_{H}\left(h_{2}\right) \neq 0$. This implies that $H$ is NI graph. On the other hand, if $g_{1} g_{2} \in E(G)$ and $h_{1}=h_{2} \in V(H)$, we have two possible cases as follows:

(a) $g_{1} \in U$ and $g_{2} \in V(G)-U$. So, $\operatorname{deg}_{G(U) \sqcap H}\left(\left(g_{1}, h_{1}\right)\right)-\operatorname{deg}_{G(U) \sqcap H}\left(\left(g_{2}, h_{2}\right)\right)=$ $\operatorname{deg}_{G}\left(g_{1}\right)+\operatorname{deg}_{H}\left(h_{1}\right)-\operatorname{deg}_{G}\left(g_{2}\right)$ and since $G(U) \sqcap H$ is NI graph, $\operatorname{deg}_{G}\left(g_{1}\right)+$ $\operatorname{deg}_{H}\left(h_{1}\right)-\operatorname{deg}_{G}\left(g_{2}\right) \neq 0$. This means that $\operatorname{deg}_{G}\left(g_{2}\right)-\operatorname{deg}\left(g_{1}\right) \neq \operatorname{deg}_{H}\left(h_{1}\right)$.

(b) $g_{1}, g_{2} \in U$ or $g_{1}, g_{2} \in V(G)-U$. In this case, we have $\operatorname{deg}_{G(U) \sqcap H}\left(\left(g_{1}, h_{1}\right)\right)-$ $\operatorname{deg}_{G(U) \sqcap H}\left(\left(g_{2}, h_{2}\right)\right)=\operatorname{deg}_{G}\left(g_{1}\right)-\operatorname{deg}_{G}\left(g_{2}\right)$ and since $G(U) \sqcap H$ is NI graph, 
$\operatorname{deg}_{G}\left(g_{1}\right)-\operatorname{deg}_{G}\left(g_{2}\right) \neq 0$. This implies that $\operatorname{deg}_{G}\left(g_{1}\right)-\operatorname{deg}_{G}\left(g_{2}\right) \neq 0$, for each $g_{1} g_{2} \in E(G)$ such that $g_{1}, g_{2} \in U$ or $g_{1}, g_{2} \in V(G)-U$.

This completes the proof.

Theorem 3.7. If $G$ and $H$ are NI nontrivial graphs and there are no edges $g_{1} g_{2} \in$ $E(G), h_{1} h_{2} \in E(H)$ such that $\operatorname{deg}_{G}\left(g_{1}\right)=\operatorname{deg}_{H}\left(h_{1}\right)$ and $\operatorname{deg}_{G}\left(g_{2}\right)=\operatorname{deg}_{H}\left(h_{2}\right)$, then $G \otimes H$ is NI graph.

Proof. Let $G$ and $H$ be NI nontrivial graphs and there be no edges $g_{1} g_{2} \in E(G)$, $h_{1} h_{2} \in E(H)$ such that $\operatorname{deg}_{G}\left(g_{1}\right)=\operatorname{deg}_{H}\left(h_{1}\right)$ and $\operatorname{deg}_{G}\left(g_{2}\right)=\operatorname{deg}_{H}\left(h_{2}\right)$. If $u \in V(G)$ and $v \in V(H)$, then by definition of strong product, $\operatorname{deg}_{G \otimes H}((u, v))=\operatorname{deg}_{H}(v)+$ $\operatorname{deg}_{G}(u)+\operatorname{deg}_{G}(u) \operatorname{deg}_{H}(v)$. Suppose $\left(g_{1}, h_{1}\right)\left(g_{2}, h_{2}\right) \in E(G \otimes H)$. If $g_{1}=g_{2}$ or $h_{1}=h_{2}$, it is clear that $\operatorname{deg}_{G \otimes H}\left(\left(g_{1}, h_{1}\right)\right)-\operatorname{deg}_{G \otimes H}\left(\left(g_{2}, h_{2}\right)\right) \neq 0$. On the other hand, if $g_{1} \neq g_{2}$ and $h_{1} \neq h_{2}$, so $g_{1} g_{2} \in E(G)$ and $h_{1} h_{2} \in E(H)$. Since $G$ and $H$ are NI graphs and $\operatorname{deg}_{G}\left(g_{1}\right) \neq \operatorname{deg}_{H}\left(h_{2}\right)$ and $\operatorname{deg}_{G}\left(g_{2}\right) \neq \operatorname{deg}_{H}\left(h_{1}\right)$, thus $\operatorname{deg}_{G \bowtie H}\left(\left(g_{1}, h_{1}\right)\right)-$ $\operatorname{deg}_{G \bowtie H}\left(\left(g_{2}, h_{2}\right)\right) \neq 0$. This completes the proof.

Acknowledgment: The research of HBW and HSR is partially supported by University Grants Commission, Govt. of India under UPE FAR-II grant No. F 14-3/2012 (NS/PE). The research of ARA is partially supported by the University of Kashan under grant No. 364988/50.

\section{REFERENCES}

[1] Y. Alavi, G. Chartrand, F. R. K. Chung, P. Erdos, H. L. Graham and O. R. Oellermann, Highly irregular graphs, J. Graph Theory, 11 (1987) 235-249.

[2] M. Arezoomand and B. Taeri, Applications of generalized hierarchical product of graphs in computing the Szeged index of chemical graphs, MATCH Commun. Math. Comput. Chem. 64 (2010) 591-602.

[3] L. Barriére, F. Comellas, C. Dafló and M. A. Fiol, The hierarchical product of graphs, Discrete Appl. Math. 157 (2009) 36-48.

[4] L. Barriére, C. Dafló, M. A. Fiol and M. Mitjana, The generalized hierarchical product of graphs, Discrete Math. 309 (2009) 3871-3881.

[5] R. Balakrishanan and A. Selvan, $k$-neighbourhood regular graphs, Graph theory and its applications, Tirunelveli, 1996, pp. 35-45, Tata McGraw-Hill, New Delhi, 1997.

[6] S. G. Bhragsam and S. K. Ayyaswamy, Neighbourly irregular graphs, Indian J. Pure Appl. Math. 35(3) (2004) 389-399.

[7] R. Hammack, W. Imrich and S. Klavžar, Handbook of Product Graphs, Second edition, Taylor \& Francis Group, 2011.

[8] F. Harary, Graph Theory, Addison Wesley, Reading, 1969.

[9] M. Tavakoli, F. Rahbarnia, M. Mirzavaziri, A. R. Ashrafi and I. Gutman, Extremely irregular graphs, Kragujevac J. Math. 37(1) (2013) 135-139.

[10] M. Tavakoli, F. Rahbarnia and A. R. Ashrafi, Further results on hierarchical product of graphs, Discrete Appl. Math. 161 (2013) 1162-1167.

[11] M. Tavakoli, F. Rahbarnia and A. R. Ashrafi, Note on strong product of graphs, Kragujevac J. Math. 37(1) (2013) 187-193. 
${ }^{1}$ Department of Computer Science, KARNATAK UNIVERSITY, DHARWAD - 580003, INDIA

E-mail address: walikarhb@yahoo.co.in

${ }^{2}$ Department of Mathematics,

Shaikh College of Engineering and Technology, Bhootramanhatti, Belgaum - 591113, India

E-mail address: sabeena_h@yahoo.co.in

${ }^{3}$ Department of Mathematics,

KARNATAK UNIVERSITY,

DHARWAD - 580003, INDIA

E-mail address: hsramane@yahoo.com

${ }^{4}$ Department of Mathematics,

FERdowsi University of MASHHAD,

P. O. Box 1159, MashHad 91775, Iran

E-mail address: m.tavakoly@alumni.ut.ac.ir

${ }^{5}$ Department of Pure Mathematics, Faculty of Mathematical Sciences, UNIVERSITY OF KASHAN, KASHAN 87317-51167, IRAN

E-mail address: ashrafi@kashanu.ac.ir 